\title{
The Feasibility and Methodology for Water and Land Paintings in the Study of the Ming Dynasty Costumes
}

\author{
Xiangyang $\operatorname{Bian}^{1} \&$ Meng $\mathrm{Niu}^{1,2}$ \\ ${ }^{1}$ Department of Fashion \&Art Design, Donghua University, Shanghai 200051, China \\ 2 Department of Art and Art History, University of California, Davis, CA95616, USA \\ Correspondence: Xiangyang Bian. Tel: 1-370-171-5417. E-mail: bianxiangyang@163.com
}

Received: October 22, 2017

Accepted: November 21, 2017

Online Published: December 27, 2017

doi:10.5539/ass.v14n1p136

URL: https://doi.org/10.5539/ass.v14n1p136

\begin{abstract}
Chinese Water and Land painting contains lots of figure costume modeling, providing intuitive and vivid image data for the study of ancient costumes. It is a new medium for the study of Chinese ancient costumes. This paper analyzes the feasibility and methodology for Water and Land paintings in the study of the Ming Dynasty. With the Ming costumes in the Water and Land Paintings, this paper discusses the shape, color, texture and fabric patterns of the ancient dresses. The feasibility of using Water and Land Paintings to study ancient costumes is further analyzed in this paper. This paper emphasizes the importance of ancient dresses in Water and Land Painting for the study of its wearing effect, and the specific methods of research that are put forward.
\end{abstract}

Keywords: Water and Land Paintings; the Ming Dynasty costumes; feasibility; methodology; textual research

\section{Introduction}

The subject of the research of the costumes in China during the Ming Dynasty via Water and Land Paintings, until now, still is not drawing academic attention. There are only a few people who do this research both domestically and overseas. This research can be considered as the unknown side of fashion culture. There are two ways to improve. First, by looking up literature, data, and informational methods that no one has found yet through Water and Land Paintings to research of costumes in China during the Ming Dynasty. Second, by interviewing many acknowledged experts in the field, including Professors of costume history studies. These Professors include Professor Xiangyang Bian, Professor Feng Zhao, Professor Xiaoyun Dai and Professor Jincheng Su who are experts on the Water and Land Paintings. Additionally, I interviewed the University of California, Davis Professors Katharine P. Burnett and Susan B Kaiser.

Water and Land Painting is a kind of ancient traditional religious Chinese painting. Since appearing in the ancient books and paintings of the Tang Dynasty, and after several generations of development, the Ming Dynasty became the golden age, and more representative, normative and secularized (Dai, 2009, p.2). Water and Land Paintings contain lots of social customs. The shape, colour and pattern of the costumes by its detailed description, provides useful material for the study of ancient costume. (Su, 2009, p.103). Most of the existing Water and Land Paintings in 21st century are from the Ming dynasty (Huang, 2006, p.100) . It is really meaningful to see these mural paintings of the Ming Dynasty. Craig Clunas raised the question in the book Pictures and Visuality in Early Modern China: What is Chinese Painting? Water and Land Painting of Divinities of Nature makes sense (Clunas, 2011, p.18). From the root causes of the identity of the characters in water and land paintings, to wearing clothes, to dressing up and the folklore, social culture, religious beliefs and the inherent characteristics of the civil to representation of the scene (Wang, 2011, p.118). The project focuses on costume research of the Ming Dynasty. According to the identity of the character divided into the Official Costume and Civilian Costume. The research of ancient costume focuses on several aspects, including the shape of the costume, cap crown/headwear, color of costume, design pattern, and finally the fabric texture. In the meanwhile, it also analyzes and summarizes the characteristics of the performance techniques of water and land paintings. This is without a doubt a subject worthy of study that the Professors recognize no one has researched before. Therefore, through this we will be able to make contributions to Chinese costume history.

\section{The definition of the term}

It is necessary to define some of Water and Land Paintings' basic terms, location and image materials in order to 
research about Chinese ancient costume.

\subsection{Water and Land Painting}

Water and Land Painting is a kind of ancient traditional religious Chinese painting that mainly includes murals and scroll paintings. As a kind of painting used in the ancient Chinese traditional ceremony, Water and Land Painting dates back to the Three Kingdoms period and developed in the period of the Yuan, Ming and Qing dynasties. Widely distributed in the northern part of China, Water and Land Painting is the precious heritage of Chinese religion and traditional culture. Water and Land Painting contains lots of religious information, costume culture and social customs etc., providing useful material for the study of ancient costume. There are several manifestations of Water and Land Painting: murals, scroll painting, stone painting and etc.

\subsubsection{Water and Land Mural Paintings}

The preserved Water and Land Mural Painting are mainly distributed in the northern part of China. The Water and Land Mural Paintings of the Yuan, Ming and Qing dynasties are distributed in Hebei and Shanxi Provinces (Huang, 2006, p. 107) (see figure 1 and 2). In Hebei, it is available in Zhaohua Temple of Huaian county of Zhangjiakou, Gucheng Temple and Zhongtai Temple of Wei County, Jueshan Temple of Guyue Town of Pingshan County and Pilu Temple of Shijiazhuang City. In Shanxi, Water and Land Mural Paintings are preserved in Qinglong Temple of Jishan County, Guangsheng Temple of Hongdong County, Zishou Temple of Lingshi County, Yunlin Temple of Yanggao County, Princess Temple of Fanzhi County, Yongan Temple of Hunyuan County, Wenshu Temple of Taihuai Town of Wutaishan City, Yuanzhi and Jingxin Temple of Taigu County, Jixiang Temple of Lingchuan County and the north Buer Temple of Taiyuan City. It also exists in other provinces, such as Xingfo Temple of Gongyi City of Henan province, Shengshou Temple of Dazu District of Chongqing City and etc.

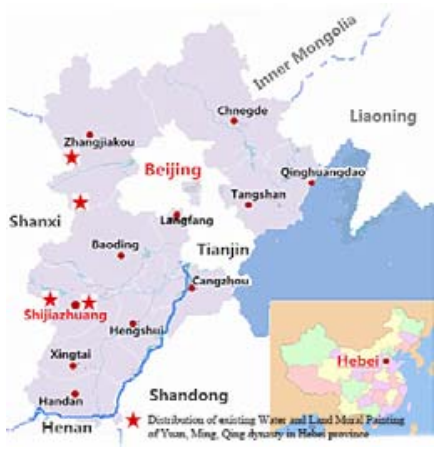

Figure 1. Distribution of existing Water and Land Mural Painting of Yuan, Ming, Qing dynasty in Hebei province

\subsubsection{Water and Land Scroll Paintings}

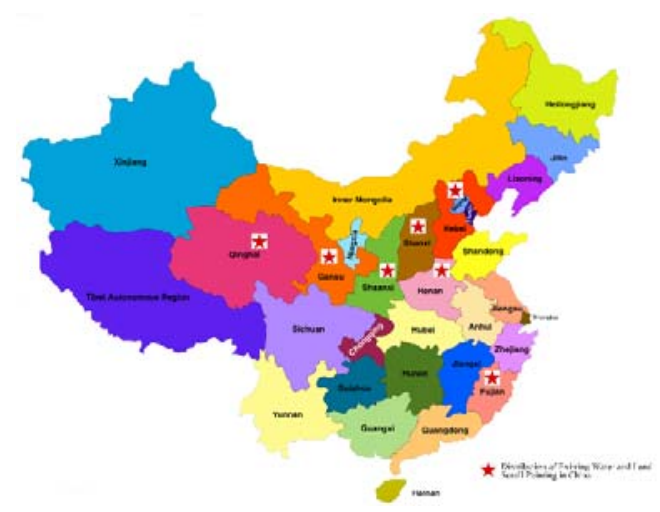

Figure 3. Distribution of Existing Water and Land Scroll Painting in China

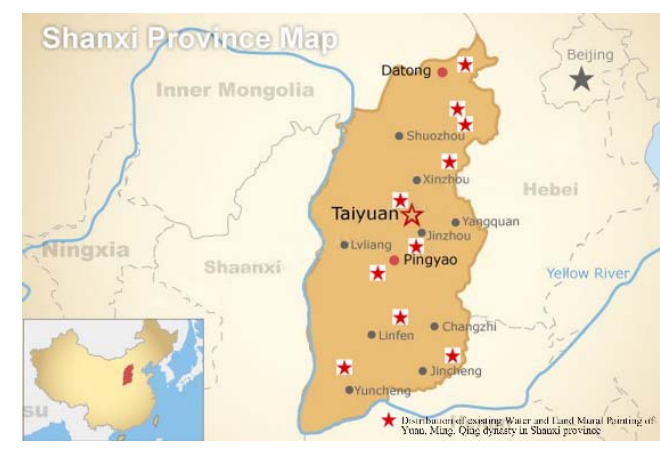

Figure 2. Distribution of existing Water and Land Mural Painting of Yuan, Ming, Qing dynasty in Shanxi province

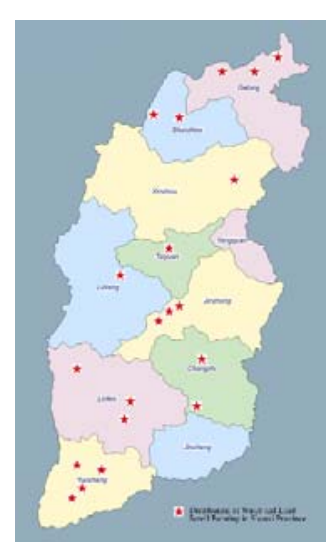

Figure 4. Distribution of Water and Land Scroll Painting in Shanxi Province

The preserved Water and Land Scroll Paintings are mainly come from the Ming dynasty and the Qing dynasty (Huang, 2006, p. 99) (see figure 3 and 4). From the north to the south and from the east to the west, the water-and-land scroll painting is distributed in Gansu, Qinghai, Beijing (Capital Museum and Palace Museum 
keep lots of Water and Land scroll painting of the Ming dynasty and the Qing dynasty), Shanxi (from the north to the south, it distributes in Counties of Yanggao, Datong, Youyu, Shuozhou, Pianguan, Xinzhou, Taiyuan, Jiao City, Taigu, Qi County, Pingyao, Xi County, Huozhou, Changzhi, Hongdong, Gaoping, Jishan, Houma, Wenxi, Yuncheng), Shanxi, Henan and Fujian.

A great amount of Water and Land scroll paintings are preserved in foreign countries, such as Royal Ontario Museum of Toronto in Canada, Metropolitan Museum of Art in America, Museum of Pennsylvania University, Cincinnati Art Museum, Tokyo National Museum in Japan and Guimet Museum in France.

\subsection{The research of the costume in Ming Dynasty}

The official and civilian costumes of the Ming Dynasty are taken as study objects. Most of the existing Water and Land Paintings in 21st century are from the Ming and Qing dynasties, and many Water and Land Scroll Paintings are kept in temples of Shanxi and Hebei provinces. In these scroll paintings, the painted figures and clothes are various, abundant, gorgeous, and vivid (Cammann, 1964, pp.38- 47). Most of the painting figures are in gorgeous Ming clothes, some are in Yuan or Tang style dress, which reflects the characteristics of figure painting in Ming Dynasty. The shape, color, embroidery pattern, ornament and wearing effect of the Ming dress are all presented in Water and Land Paintings. The clothes of modern Chinese drama are similar to the clothes that the figures of Water and Land Paintings wear. Therefore, Water and Land Paintings can provide data for the study of Chinese drama history.

\subsection{Image data}

Image data refers to Water and Land Painting and other art works which provide information of the clothing. This paper uses the archeological materials, document literatures and image data of Water and Land Painting as the basis for studying the ancient costume history. These pictures and images provide affluent visual art and modeling creation for exploring Chinese ancient costume. The image data in this paper discusses the preserved Water and Land Paintings, and especially the Water and Land Paintings of the Ming dynasty, which are in the forms of mural painting and stone painting. Of all the aforementioned, the stone paintings are of the minority (Dai, 2009, p.4).

\subsection{Realistic degree}

As the true portraiture of the objects, image data has certain consistency with the object. However, with the craftsman's technique, the use of creation, personal characteristics and understanding of painting vary. The Chinese Water and Land paintings are not the only methods that can be used to illustrate the Ming Dynasty costume style. This paper will use other forms of Chinese paintings to delineate this. Painters draw the social customs as a way to describe the details of the style and color of the figure clothes of that time. Besides drawing in accordance with the previous few dynasties methods of Water and Land paintings, most of the saints' clothes are drawn according to the costume system of the time of the Ming Dynasty. Doing this provides vivid and direct data for the study of Chinese ancient costume (Su, 2009, p.104). This paper proposes the concept of realistic degree to describe the true degree of the image data of Water and Land Paintings for the real relics.

\section{The feasibility for Water and Land Paintings in the study of the Ming Dynasty costumes}

As for the methods for studying ancient costumes, this paper is mainly corroborated by cultural relics, cultural documents and image data. The study material of the costumes can be divided into text material and non-text material according to its' existing form. There are many literature works involving costumes, but the literature works are not completely consistent with the facts. The non-text material includes clothing, weaving, imaging, scroll painting, terracotta army and decorative ware relevant to clothes. Compared with text material, the non-text material is more real and direct. It has strong evidence of costume history (Bian, 2000, pp.23-24). As for the function of image in history study, image can present the history in a more direct and reliable way than literature data. French historian Hippolyte Taine declared confidently in a letter to his mother that he would throw historical documents away. He would write an Italian history taking painting as historical resources. He found that "instead of acting and writing, people tend to express themselves more clearly and earnestly in decoration, stigma and dome” (Cao, 2007, p.36). Craig Clunas raised the question in the book Pictures and Visuality in Early Modern China: What is Chinese Painting? Water and Land Painting of Divinities of Nature make sense (Craig, 2006, p.18).

Mr. Congwen Shen made a great contribution to the study of Chinese ancient costume. His Chinese costume culture monograph "Ancient Chinese Clothing Research" extensively makes use of images, literature, and ethnological materials or other handed down cultural relics as circumstantial research methods. It respects historical evidence and searches historical truth in multiple ways. He wrote the book in an objective light. With 
the cap description of people from all walks of life during the Ming dynasty in stone paintings "Sancai Tuihui" and "Imperial Benevolence" mentioned in the book, with "Ming Huiyao", "Seven Revision Draft" and other literatures. This book studies the symbolic meaning. The aesthetic idea and apparel culture's connotation of the Ming dress. The book "Chinese ancient costume History" written by Zhou Xibao is a historical book of high academic level. Mainly based on historical documents to verify the recorded image data, his paper verified the validity of the contents recorded in literature according to the images collected in his investigations. It shows the importance of mutual verification of image and literature for the study of costume history. Direct access to archaeologically authenticated textiles has not been possible, and, as a result, one of the main sources of information has been summary reports published in Chinese from archaeological excavations and pictures (Zhong \& Hann, 1991, pp.18-23). If one judges the image data of his subjective consciousness without the systemic discuss of its feasibility, and the establishment of rule-based coordinates, how much value does this image data have for a lot of the relics and literature of clothing? What is the unique artistic value of Water and Land Painting compared to that of cultural relics and literature?

The ancient costume is a touchable and observable object. As a practical item of the people of that time, it also can be researched in person by the modern scholars. While in contrast, the manifested patterns in the clothes in the image data of Water and Land Paintings match the description of the clothes during the real-life time of those days. We can see from the pictures that the painters are skillful and precise; the outline and rendering are very delicate. The lines are smooth and mild. The costumes' weaving and its pattern details are presented vividly. With solid basic skills, rich experience and creativity, they record by pen what they saw and what they felt, making people feel as if they were there in the scene. In the investigation of temples of Shanxi, the figure image, clothes detail, weaving pattern and ornaments are drawn in colorful colors, depicting the gold and silver and other traditional techniques. The noble and glorious artistic characteristics embrace the decorative features, with strong folk art characteristics. The modern scholars, after seeing the arts expressing the painters' feelings, will feel the painters' feelings, so as to enrich the costume culture theory. This process can be described by pictures (see figure 5). Of course, for the different craftsmen of Water and Land Paintings, their purpose of creation and creative attitude is not the same, so is the artistic expression. Even if they are drawn by the same person, they vary in different subjects. Although there are such differences, the realistic exquisite murals exist in every age. Some authors present the true life of their times, which makes our research feasible (Bao, 2004, p.51).

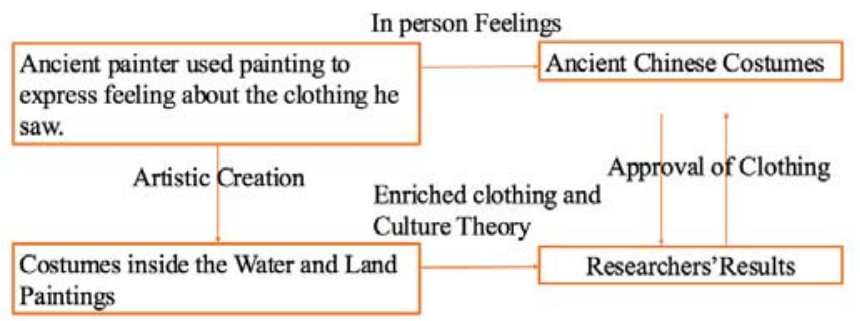

Figure 5. Feasibility and Method Flow Chart

\section{Some aspects of using Water and Land Painting to study ancient costumes}

There are various studies on the history of ancient costume. Clothing textiles, fashion culture and aesthetics can be included in the scope of the study, but these are not the focus of research. The clothes reflected by murals, scroll painting and sculpture image data is not the focus of this study. This paper studies the aspects of dress form, crown jewelry, color, pattern etc.

\subsection{The shape of the costumes}

The Portraits painting Tian Fei Sheng Mu Bi Xia Yuan Jun Xiang contains 8 persons (Editorial Committee of Beijing cultural relics appreciation, 2005, p.36) (see figure 6). The front right corner of it marks "Creating for Cisheng empress in Wanli Jiyou Year of the Ming dynasty". It is drawn by professional painter Empress Cisheng which was commanded in Wanli year. There is the royal seal of Empress Cisheng on the painting, and the front right corner of it marks Tian Fei Sheng Mu Bi Xia Yuan Jun Xiang. The Empress and Bixia Yuanjun are in the front row, wearing a crown and a big sleeve cape. According to the retained literature and image data, the Mingfu's cape, especially for the collocation of red sleeve shirt, generally makes use of deep blue embroidery. The pleating of Ru skirt was very popular in the Ming dynasty. The decoration was also very elegant. There are fine pleats and large pleats. The Mingfu is beautiful, elegant, accessible and trustworthy, with jade in both hands. Bixia Yuanjun turns back to communicate with the goddess, which is drawn vividly. The middle two goddesses, 
with board in hands, are in gorgeous clothes and vivid expression. The back and left side of them have four female officers standing. They wear a black gauze folded napkin, decorated with flowers, beaded hair comb, hanging beads earrings. They are dressed in round collar gowns, narrow sleeves, and take the most distinctive robes of the Ming Dynasty, which has a patch on chest and back to distinguish between grades. Robes generally use lighter color, such as light pink, light green and light blue. Bow shoes are decorated with small golden flowers. The palace costume is the same as that of the Song dynasty. The characterization is exquisite, vivid and natural. They hold censer, Ruyi, fan and jade seal, following the four women. This Water and Land Painting vividly presents the lightness and elegance of women's clothes of the time. This image data reflects the beauty of the overall dynamic clothing.

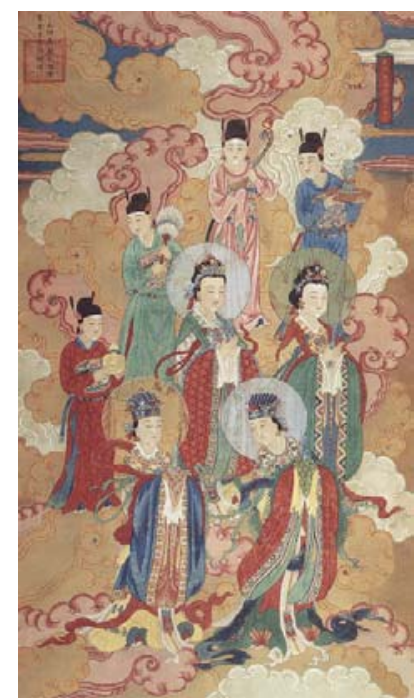

Figure 6. Water and Land Painting named as: Tian Fei Sheng Mu Bi Xia Yuan Jun Xiang. Reprinted with permission from (Editorial Committee of Beijing cultural relics appreciation, 2005)

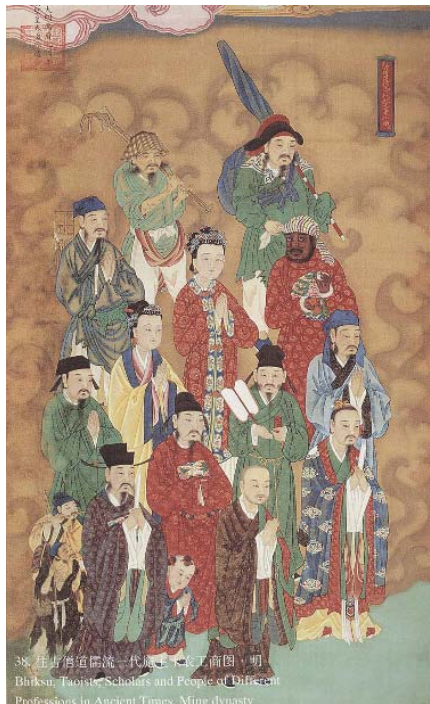

Figure 7. Wang Gu Ceng Dao Ru Liu San Dai Shi Zhu Shi Nong Gong Shang. Reprinted with permission from (Editorial Committee of Beijing cultural relics appreciation, 2005)

\subsection{Cap Crown}

Wang Gu Ceng Dao Ru Liu San Dai Shi Zhu Shi Nong Gong Shang Image (Editorial Committee of Beijing cultural relics appreciation, 2005, p.37) (see figure 7), at the left top of the picture was signed by "Empress Cao in Da Ming Wanli Ji You period", it was also painted by Wanli Emperor's mother. This painting covered a wide range of topics with rich content. It authentically revealed the current features of the general public lives. The picture has a fixed way of structuring all of the characters' positions. With flexible combinations base on the character's social status, there are 16 people in the picture and they are divided into four groups. At the top of level there depicts the workers, farmers, and businessmen. The first right person wears Mongolian hats and Yunjin, the hats and the scarf reflect distinctive local and ethnic features. Although the Yuan Dynasty was destroyed, Mongolian clothes were dispersed out in different forms. In Ming dynasty, civilians often in cyan, purple, blue and white. Portuguese called Gaspar da Cruz shaped the image in the Book of China with costume from Ming Dynasty; ordinary citizen usually wear black cotton robes, while poor people with white, simply because it is cheaper (Brook, 1998, pp.3-4). The top part of the picture has a young man with a cyan cross-over collar and narrow sleeves short gown. He is also wearing over-the-knee white pants while carrying rakes, hoes and spades which are simple farming tools. The image of the working people in the Ming dynasty are like painting $\mathrm{MoPu}$. It is convenient for farmer in the short gown to work. On the left, the craft person wears the Pingjin Ze, cyan cross-over collar and narrow sleeves gown, with the hands in prayer position. The second group depicts the image of two women, with the graceful, beautiful and Gorgeous dress. One of the women has her hair pulled back into a peony updo. Women in Ming Dynasty liked to wear wigs with Huachai and Dianhua, and the ladies wore band collar narrow sleeves with a geometry flower pattern. The Beizi is a common clothing in the women's civil society of Ming Dynasty. There are narrow sleeves and wide sleeves. The wide sleeves of Beizi is usually worn on important occasions, while in private life narrow sleeves are worn instead (Yuan, 2007, pp.181-212). The edge of Beizi is decorated with different patterns and colors, with a red coat embroidered with a blue-and-white flower. From the Wanli years we can see the how the dress design became more and more decorative, which is different from Tang and Song Dynasties. For fixing the edge of clothes and decoration, a button is used to connect the two sides fashionably. This way has been used instead of lines with knots to 
connect garment sections for thousands of years.

From the picture we found that in order to conveniently work, famers and craft persons tighten their belts, which is made of cotton. In the early part of the Ming Dynasty, the officials belt had two function: real belt and decoration belt. As this was the case in the early period, in the late period, the officials belt did not have the function of the traditional belt. It was a decoration that shows the wearer's status. The belts of Chinese modern drama are very similar to those in the water and land paintings (Ding, 2014, pp.1035-1039). When it mentioned officials in uniforms in the notes of historical data Yueshibian, which recorded the economic life in the late time of Ming Dynasty, the officials often held the leather gasket strap with hands to show a mighty and straight spirit state. In the book, it reads "the gasket strap is made of leather, wrapped in green silk, ornamented by jade, rhinoceros horn, cyanine, and untold amount of the gold and silver..., the belt is wide and round so it does not girdle the waist. The round collar and two flanks are with a towel on which a fine button suspends on either side, which can reflect majesty.” In Ming Dynasty, the standard leather belt had a block of three square tablets in the front, with a symmetrical combination, attached to four small rectangular accessories and three peach-shaped rounds between the two accessories on the opposite sides, also with 2 fish tail and seven rows behind the leather belt (Ch'iu, 2014, pp.555-631). The patterns, jade ornaments and wat board materials of the waist leather belt are not the same because of the grade distinctions of officials. The specific shape is recorded in Ming History Requirements for Wearing. First-rank officials wore seven liangs. Their waist leather belt was decorated with jade, the ribbon was a four color Phoenix flower brocade which was compiled with yellow, green, red and purple brocade. The jade was tied to the ribbon, and the wat board was made of ivory. Second-rank officials wore six liangs and a leather belt around the waist with rhino jewelry which was tied to the ribbon, and the rest was the same as first-rank officials. Third-rank officials wore five liangs with a leather belt around the waist with was decorated with gold, and with jade which was used as an accessory. The ribbon was a four color cloud crane flower brocade, which was combined with yellow, green, red and purple brocade with gold tied to the ribbon. The wat board was made of ivory. Fourth-rank officials wore four liangs with their leather belt decorated with jade, and glaze was used as an accessory. The rest was the same as the third-rank officials. Fifth-rank officials wore three liangs with their leather decorated with silver, and glaze was used as an accessory. The ribbon was a carved brocade which was compiled with yellow, green, red and purple brocade. Silver-plating was tied to the ribbon, and the wat board was made of ivory. Sixth and seventh rank officials wore two liangs with a waist leather belt decorated with silver, and with glaze used as an accessory. The ribbon was a long-tailed flycatcher with a three color flower brocade which was compiled with yellow, green and red brocade. Silver was tied to the ribbon, and the wat board was made of wood of Chinese scholartree. Eighth and ninth rank officials wore one liang, and the waist leather belt was decorated with horn-like material. Glaze was used as an accessory. The ribbon was a Xi Chi two color flower brocade which was compiled with yellow and green brocade. Copper was tied to the ribbon, and the wat board was made of wood of Chinese scholartree (Zhang, 1974, pp.1634-1635).

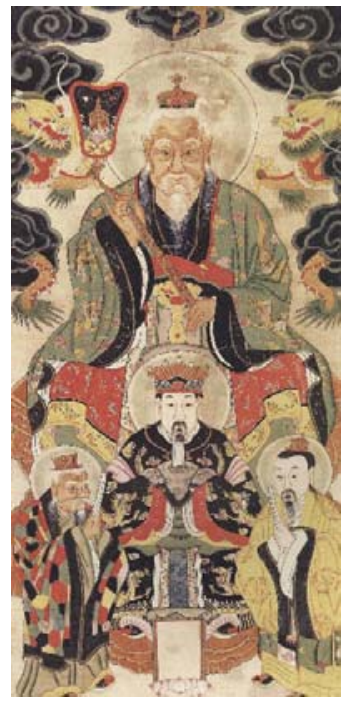

Figure 8. Taiqing Moral God Image. Reprinted with permission from (Hu, Binbin \&Wu, Can, 2013)

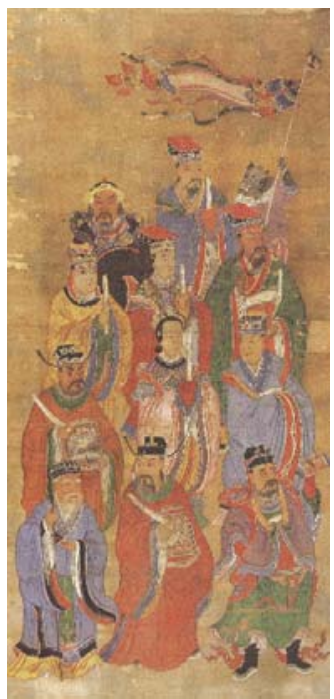

Figure 9. The God Images of Taoism. Reprinted with permission from (Hu, Binbin \& Wu, Can, 2013)

Underneath the picture are officials and scholars. The left one is wearing an unfolded foot headwrap and Tuan gown with a round collar. The official robes place the gayer patch in the chest and back area to distinguish rank 
order which is the characteristic in Ming dynasty. He also wears the belts and carries the wat board. There is a man in the middle of the picture who is wearing a right lapel cross collar gown, and a few belts. His two hands inserted in the sleeve of the opposite and has a peaceful look on his face. The man wears a headwrap, right lapel cross collar gown, and ties the big belt around his waist. The right hand holds the fan and looks straight ahead. The one on the right wears Ping style headwrap. The style of dress is slanting collar, and the sleeves are wide. The collar band is sewed broadside. He is happy and pleased with himself. There is a child below. The child shows the style of children's dress in the Ming Dynasty. The boy shaves off some of his hair, and leaves the rest of his hair to be fixed into a bun or braid. He wears a cross collar with trousers below, and ties the big belt round waist and wears boots. Having similarities to the image of children in the Lantern Festival picture in Ming Kenso years, these paintings share common elements such as children and toys (He, 2013, p.151). On the bottom is a monk. A mystical image. He wears wide sleeves, big gown, colorful auspicious cloud pattern shirt with a neckline. Cuffs and hem of the gown are designed with geometric patterns. All of these, can be used as one of the bases for the study of ancient costume.

\subsection{Color}

Water and Land Paintings are colorful, brilliant, and strongly contrasted. They match ochre red with green. Strong colors create a strong decorative effect. The art of painting is inherited from Dunhuang frescoes. It can also be said to be the continuation of Dunhuang frescoes. Meticulous heavy color painting effect and rigorous style. It is neat and delicate, because the paint is selected from minerals. After a hundred years, the color is still bright and gorgeous, just like a new work. It is painted by thread filling technique. First the structure of the shape is outlined with dark color, and then colored is applied to the drawing. In the contrast of non-color and color in painting, like in Taiqing Moral God Image (Hu \& Wu, 2013, p.114) (see figure 8), between black, green, red yellow, etc., visual contrast is bold. When the black area is large, a heavy sense of seriousness arises. When the colored area is relatively large the picture becomes bright and colorful. In The God Images of Taoism (Hu \& Wu, 2013, p.128) (see figure 9), the whole painting is rich in color, brilliant and high in saturation. Although the visual contrast is strong, the whole effect of the picture is very harmonious, it is impressive. There are 12 people in the drawing. Seven people wear round collar gown. Four people wear cross collar gowns, and among them, 2 people are talking respectfully and politely. The picture is dominated by red and bluish-green, and these two colors match with green, pink, yellow and black. These secondary colors appear in the hat, collar, cuffs, etc. for modification. The dress itself is based on a large area of red. The edge of the blouse and sleeves are garnished with contrasting colors. The character's dress itself has a large area of red color. The edge of the blouse and sleeves are garnished with contrasting colors. All the colors aforementioned make the image stand out. Cyan gown cuffs are dotted with red which reflects the aesthetic features of folk painters. It is full of the rich flavor of life. The old man ahead wears a leather bian and cross collar big gown. The elder was very particular in his clothes. The edge of the cyan gown's collars, cuffs, and hem are black. Two large sleeves with red stickers inside match with a piece of green clothing to cover knees and yellow skirt. Appearing in a large shade of light cyan, it matches with black, red, yellow. These long tone colors form a contrast which can give people a bright and sonorous feeling with strong contrast. From the Water and Land Painting, we can get the color information intuitively, but these colors do not necessarily reflect the true colors of the clothes of the time. The creator is often subjective in using color and often uses color according to the needs of the picture. Even if color in the picture is the same as the color of the clothing of the wearer, as time changes, so does the color.

\subsection{Fabric pattern: Colorful auspicious cloud pattern, lotus pattern, cloud pattern}

Many patterns of clothing appeared in the Water and Land Painting of Ming dynasty. The decorations are very complicated, themes are diverse, and the colors are gorgeous and strong but not very extravagant in effect. Compared with other image materials, costume patterns are influenced by secular culture. From the color, content and arrangement of the pattern, we can deduce that it has a certain realism and authenticity (Chueh, 2004, pp.1576-1582). In Tiancao Six Gods Images (Editorial Committee of Beijing cultural relics appreciation, 2005, p.38) (see figure 10), this painting technique is called Gongbizhongcai. In the painting the line drawing is rich, outline is fine, gown's pattern and decorations are very delicate and precise. The figures are graceful, composition is harmonious and complete, and the headgear and ornaments are outlined in gold and silver color. Using sparse lines in addition to outline the pleats, the patterns are intricate and exquisite. They reflect the material, fabric and texture of the dress. The ribbon of the clothing and the auspicious clouds in the background are outlined by lines like willow leaves. Lines change and are dynamic. Harmony appears in a picture with the figure's dress and charm. 


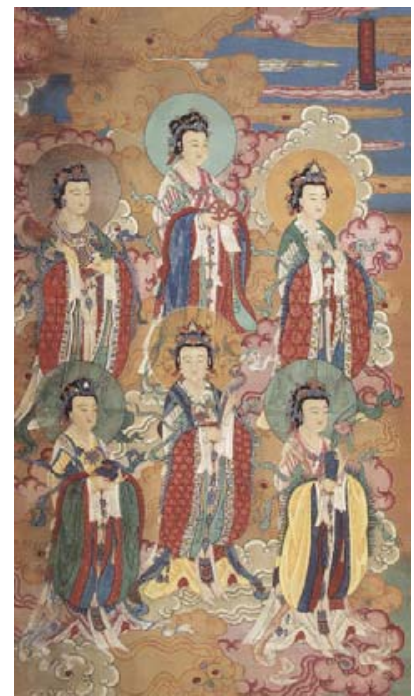

Figure 10. Tiancao Six Gods Images. Reprinted with permission from (Editorial Committee of Beijing cultural relics appreciation, 2005)

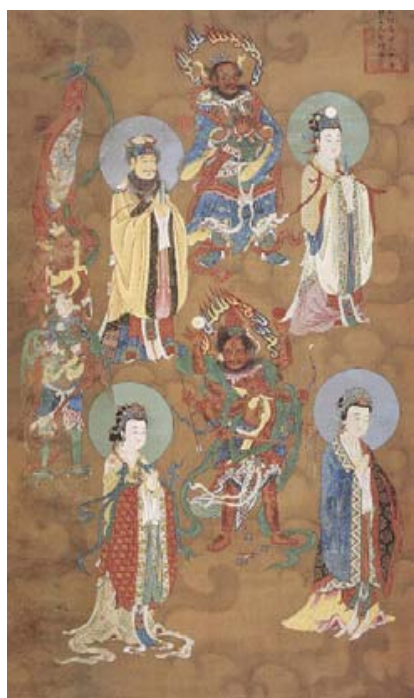

Figure11. Six Gods Images. Reprinted with permission from (Editorial Committee of Beijing cultural relics appreciation, 2005)

In Six Gods Images (Editorial Committee of Beijing cultural relics appreciation, 2005, p.40) (see figure11), the lines are very smooth in the painting of the characters in the picture. The spaces are well placed, contrast is strong, proportions of the shape are very harmonious. The image is complete. The painter carefully designs the costumes and color collocation. Very particular about it, the costumes are gorgeous in color and there are specific patterns on the clothes. Decorative patters are painted on the edge of the garment. There are four gods in the picture. The lower left god's clothing patterns show '与', geometric flower patterns, lotus patterns on the cloak, and peony flower pattern on the cuffs. The design of this character is magnificent and extravagant. It is similar to the woman in the figure painting of "Lady Carrying a Pipa" by Wu Wei (Cahill, 1978, p.105). The first to the right is a goddess in a blue, water flowing pattern robe. It uses geometric patterns as the ornament for the edge of the garment. The image is dignified and elegant, fresh and refined. The robe of the man who is in the upper part of the picture, has two pieces, the cuffs and hem. Both the cuffs and hem have fish-scale patterns. This is in contrast with the physical patterns and statues of the same period, and is also in contrast with the figure painting of contemporaries. The classic patterns of armor worn by ancient Chinese warriors can be observed. These patterns include fish-scale patterns, tortoiseshell patterns, lock patterns and cloud patterns. These all appear in the Water and Land Painting (Wang, 2014, pp.177-180). The lotus patterns, auspicious cloud patterns, geometric patterns and other patterns will repeat, but sometimes, in order to avoid mental fatigue the painter will combine the work with their own creative imagination to paint. These basic elements will be re-arranged, such as flowing cloud patterns and auspicious cloud peony patterns, etc. It has become increasingly recognized by both anthropologists and archaeologists, that patterns of all kinds can be objectively classified according to their culture characteristics (Hann, 1992, pp.579-590). In a class society, the hierarchy is distinct. Different patterns are suitable for different levels of status. Colors, patterns and sizes determine the applicable range of this kind of pattern. These can be used as the basis for the study of the costume.

\subsection{Fabric texture}

Clothing fabric has its own unique way of expression; however, the richness and shape of Chinese painting lines need to be conveyed by the brush. The beauty of the lines in the Water and Land Painting is also expressed by the change of the content of the dress. This is also a unique feature of painting. The first stroke of a character, then the pause and transition, the speed, and the virtuality and essence cause linear length, thickness, density and so on. All of these achieve the unique aesthetic taste and artistic beauty of the line. Pay attention to the combination of the technique of the brush and the content of clothing to be expressed. Plus, with the creative imagination and stylistic features of the creator, there are rich and varied lines used to express some features of ancient clothing materials. Clothing fabrics include Zhu cloth, cotton, silk and woolen goods, etc. These ancient fabric materials and textures, which are simple natural characteristics have a profound influence to and close relation with Chinese traditional painting style of costume. Focus on the details of the expression of the visual reality and the painter's style. It's not just rough grafting. It takes the specific image of the clothes as a model to paint the painting. There is a basis for communication between things. Such as in stain clothing. The texture is 
soft, and the color is bright while natural. It is consistent with the artistic expression of the figures and costumes in the Water and Land Paintings.

In Water and Land Painting, the lines in the dress of the figures are flexible and rigid, while smooth and natural. The ribbons of the dress are well spaced. They accurately and vividly reflect the texture of different materials and fabrics. In Brahman Gods Scholars, Peasants, Workers and Businessmen (see figure 12), the picture shows religious figures and secular figures in one picture. Well proportioned, rich in content, and prominent in character, while harmonious and full of vitality. The upper half depicts the Buddhist figure Brahman, while the lower half of the drawing depicts scholars, peasants, workers and businessman. "Emphasizing agriculture but restraining commerce" in Ming dynasty the peasants are of a higher class than the merchants. They can wear silk, yarn cloth, linen, and cotton cloth. Businessmen can only wear cloth. As shown in the figure, the man in the upper part, the farmer, wears a round cap brim hat, purple cross collar narrow sleeves silk pattern blouse, green ribbon around waist, and carries a rake. The one on the left wears a flat hat and a cyan cross collar narrow sleeves blouse. The businessman carries a bag and looks behind himself. The far right person in the front row wears a square top, hard design headwrap, round collar wide sleeves silk gown with patterns longer than knees, and is holding a wat board. He is an image of humility and softness. Through the image analysis of the Water and Land Paintings, painting techniques, and characteristics, it is helpful to judge the texture of the fabrics of the clothes.

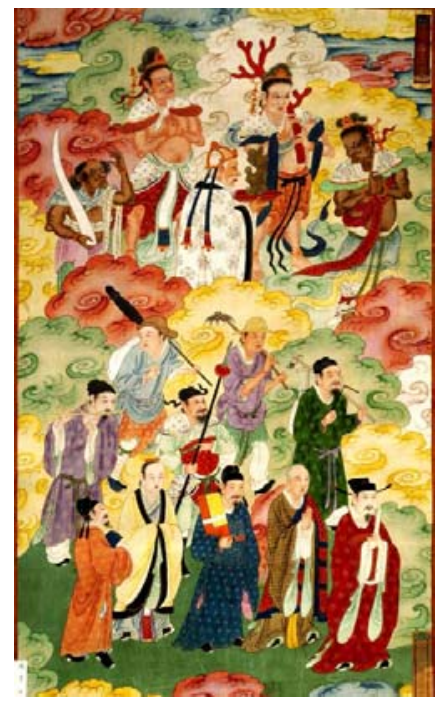

Figure13. Brahman Gods Scholars, Peasants, Workers and Businessmen. Reprinted with permission from (Shandan Museum, China)

\section{Discussion on the method of Study of ancient costume performance with Water and Land Painting}

\subsection{Observation, qualitative judgment}

Making regular judgement by observing the frescoes, scroll paintings, and image data of the Scare Pictures. First of all, in image data, the creative background, the author's identity, performance techniques, style of work, and others are included in the scope of judgment. Secondly, qualitative observation emphasizes the interpretation of patterns and meanings behind behavior and events in the study. There are four main ways of recording: description System, narrative system, map records, and process record. The main method of judgment is fieldwork, notes, a large number of original texts, pictures and recordings that are recorded in the survey and are integrated and analyzed (Chen, 2000, p.1). Thirdly, in the actual investigation, we need to strengthen the ability consciously or unconsciously. After the purpose of the investigation is made clear, through careful observation and expression of real feelings, and in addition with the aid of literature, images and interviews, we can judge the perceptual visual data qualitatively. Make the study of painting have more depth and breadth. Of course, in the investigation process, we should pay attention to the following points:

1) In the process of inspection, the environment of the site should be restored to the utmost similar version to what was observed in person. This means that before building a mock version we must prepare sufficient research conditions.

2) Use nouns and verbs to describe objective facts, and avoid adjectives with descriptive emotion and modifying nouns.

3) Do not omit any details. Sometimes this important evidence is the breakthrough point of the paper. 


\subsection{Research methods of image science}

In the analysis of these image materials, we should pay attention to the stylization in the paintings. Stylization in Chinese folk art is an indispensable essential attribute. In other words, without stylization, there would be no folk art in Water and Land Paintings. It covers all kinds of art, drama, painting, literature, etc. In ancient times, the learning of stylization was the foundation of being a painter. It includes painting techniques, composition, material, etc. It is accumulated in the work of the painter painting experience, rules and tips, in order to draw some images, there are fixed procedures. When studying the graphic data of Water and Land Paintings, we should perform a comprehensive analysis of the sum of various images of social life in the Ming Dynasty. These images should be viewed from the time of the social life and the identity of the people of the dynasty. We should incorporate the visual culture into the costumes, social culture and life to make a deeper study.

\subsection{Compare, analyze and perform on-the-spot investigation}

Comparing and observing the documents and objects cannot be limited to one single material. We need to verify the comprehensive use of various materials in many ways and angles. This paper studies the history of Chinese costumes with Water and Land Painting as its carrier. We can make horizontal comparisons of the Water and Land Painting period's frescoes, scroll paintings and image data, and at the same time, we can refer to literature records and physical objects. In this way, we will have abundant research examples to analyze all these image data and make qualitative judgments, so it is valuable to the study of Chinese dress history.

In the Literature section, we can read the ancient and modern historical Chinese documents starting from the twenty-four history books, to a variety of historical biography, notes, novels. All kinds of painting, clay figurines, stone carvings, folk art, and unearthed cultural relics. A notebook and copy book should be brought along to record the relevant records of clothing and picture in the visible materials. In this way, every little bit of vast and rich first-hand information can be recorded.

Comparisons can be carried out from the form of clothing, color, pattern, wearing effect and fabric texture, etc. The shape and fabric texture of clothing are difficult to study. Clothing fabric can have a lot of performance techniques, such as the visual effects of silk and satin which are extremely similar in being smooth and delicate (Sun\&Yuan,2014, p.59). Under the circumstances, visual image is similar to physical description and document description. We cannot completely bring out the actual expression of the fabric. Being only partially true, some have been transformed and be used at that time. Some have been completely integrated into the real world and are not recognizable. Therefore, the results reflected in the image cannot be completely true. Understanding the qualitative judgements of past relics helps to understand the past. It is believed that through this method, the historical knowledge of the true and possible objective clothing conclusions can be obtained.

\section{Conclusions}

Take Water and Land Paintings as a medium study costume in Ming Dynasty. Few studies have been conducted on this subject at home and abroad. Therefore, it is a challenge for me. The method of conducting ancient costume studies by using Water and Land Paintings is determined by the purpose of the study. Methods of verification should be done using several sources and multiple angles include images, literature, and relics. With the development of society, and the progress of science and technology, there will be newer and more scientific methods in the future practice.

\section{Acknowledgments}

The authors would like to thank Donghua University and the University of California, Davis. Also, many thanks for the supporting of 'Project Fashion Culture, History and Heritage supported by Shanghai Summit Discipline in Design' (Project number is -DD17002). Meanwhile, thanks for the editor and the readers of Asian Social Science.

\section{References}

Bao, Mingxi. (2004). The Feasibility and Methodology in the research of the China's ancient silk in Dunhuang Frescoes and sculpture. Journal of Dunhuang Research. vol.1, 51.

Bian, Xiangyang. (2000). Research methods of Chinese clothing history. Journal of China textile university, vol.4, 23-24.

Brook, T. J. (1998). The Confusions of Pleasure: Commerce and Culture in Ming China, 3-4. California, Oakland: University of California Press.

Cahill, J. F. (1978). Parting at the Shore: Chinese Painting of the Early and Middle Ming Dynasty, 1368-1580. Weatherhill, 2, 105. 
Cammann, Schuyler. (1964). A Ming Dynasty Pantheon Painting. Archives of the Chinese Art Society of America, vol. 18, 38-47.

Cao, Yiqiang. (2007). The Vision of Art History, 36. Hangzhou: China Academy of Art Press.

Chen, Yao (2000). Study of Classroom Observation Methods,1. East China Normal University.

Ch'iu, CL. (2014). Warmth, Ostentation, and Power: A Culture History of Valuable Furs in the Ming Dynasty. Bulletin of the Institute of History and Philology Academia Sinica, 80, 555-631.

Chueh, BF. (2004). The Integration of Costume and Fabric Design Technology in Chinese Ming Dynasty (AD 1368-1644). Quality Textiles for Quality Life, vols.1-4, 1576-1582.

Craig, Clunas. (2006). Pictures and Visuality in Early Modern China, 18. London: Reaktion Books.

Dai, Xiaoyun. (2009). Research of Buddhist Water and Land paintings, 2, 4. Beijing: China Social Sciences Press.

Ding, Y. (2014). On the Decoration and Symbolization of Chinese Ancient Official Uniform in Ming and Qing Dynasties. Proceedings of the 2014 International Conference on Mechatronics, Electronic, Industrial and Control Engineering, 5, 1035-1039.

Editorial Committee of Beijing cultural relics appreciation. (2005). Water and Land paintings in Ming and Qing Dynasty, 36, 37,38,40, 41. Beijing: Beijing Art Photography Press.

H. Zhong \& M. A. Hann. (1991). Textile Production in China between the Han Dynasty and the Tang Dynasty. The journal of textile institute, vol.82, 18-23. DOI: 10.1080/00405009108658733

He, Yuming (2013). Home and the world: editing the 'Glorious Ming' in woodblock-printed books of the sixteenth and seventeenth centuries, 151. Massachusetts, Boston: Harvard University Asian Center Press.

Hu, Binbin and Wu, Can. (2013). Dan Qing Jiao Hua, 114, 128. Hunan: Hunan University Press.

Huang, He. (2006). Water and Land paintings of Yuan Ming Qing II. Journal of Buddhist Culture, vol.3, 99.

Huang, He. (2006). Water and Land paintings of Yuan Ming Qing. Journal of Buddhist Culture, vol.2, 100, 107.

M. A. Hann. (1992). Symmetry in Regular Repeating Patterns: Case Studies from Various Cultural Settings. The journal of textile institute, vol.83, 579-590. DOI: 10.1080/00405009208631233

Su, Jincheng. (2009). Research of Water and Land painting images, 103-104. Southeast University.

Sun, Peiyan and Yuan, Xuanping. (2014). Research of Pattern Textiles in Water and Land paintings, 59. Journal of Silk.

Wang, C. (2014). Conservation study of Ming dynasty silk costumes excavated in Jiangsu region, China. Studies in Conservation, vol.59, 177-180. DOI: 10.1179/204705814X13975704319154

Wang, Jianguo. (2011). Research of Water and Land painting Cultural Anthropology,118. Journal of Art and Architecture.

Yuan, Zujie. (2007). Dressing for power: Rite, costume, and state authority in Ming Dynasty China. Frontiers of History in China, 2(2), 181 - 212. DOI: 10.1007/s11462-007-0012-x

Zhang, Tingyu. (1974). History of Ming, 1634-1635. Beijing: Zhonghua Press.

\section{Copyrights}

Copyright for this article is retained by the author(s), with first publication rights granted to the journal.

This is an open-access article distributed under the terms and conditions of the Creative Commons Attribution license (http://creativecommons.org/licenses/by/4.0/). 